Article

\title{
Simple and Efficient AlN-Based Piezoelectric Energy Harvesters
}

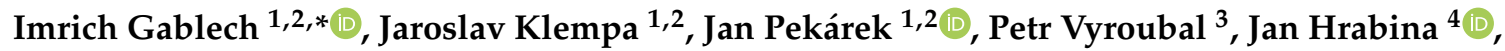 \\ Miroslava Holá ${ }^{4}{ }^{(}$, Jan Kunz ${ }^{5}$, Jan Brodský ${ }^{1}$ and Pavel Neužil ${ }^{6}$ (D) \\ 1 Central European Institute of Technology, Brno University of Technology, CZ-61600 Brno, Czech Republic; \\ ja.klempa@gmail.com (J.K.); pekarek@vutbr.cz (J.P.); jan.brodsky@ceitec.vutbr.cz (J.B) \\ 2 Department of Microelectronics, Faculty of Electrical Engineering and Communication, \\ Brno University of Technology, CZ-61600 Brno, Czech Republic \\ 3 Department of Electrical and Electronic Technology, Faculty of Electrical Engineering and Communication, \\ Brno University of Technology, CZ-61600 Brno, Czech Republic; vyroubal@feec.vutbr.cz \\ 4 Institute of Scientific Instruments, Czech Academy of Sciences, CZ-61264 Brno, Czech Republic; \\ hrabina@isibrno.cz (J.H.); hola@isibrno.cz (M.H.) \\ 5 Department of Control and Instrumentations, Faculty of Electrical Engineering and Communication, \\ Brno University of Technology, CZ-61600 Brno, Czech Republic; kunzj@feec.vutbr.cz \\ 6 Department of Microsystem Engineering, School of Mechanical Engineering, Northwestern Polytechnical \\ University, Xi'an 710072, China; pavel.neuzil@gmail.com \\ * Correspondence: imrich.gablech@ceitec.vutbr.cz; Tel.: +420-54114-9221
}

Received: 3 January 2020; Accepted: 27 January 2020; Published: 28 January 2020

check for updates

\begin{abstract}
In this work, we demonstrate the simple fabrication process of AlN-based piezoelectric energy harvesters $(\mathrm{PEH})$, which are made of cantilevers consisting of a multilayer ion beam-assisted deposition. The preferentially (001) orientated AlN thin films possess exceptionally high piezoelectric coefficients $d_{33}$ of $(7.33 \pm 0.08) \mathrm{pC} \cdot \mathrm{N}^{-1}$. The fabrication of $\mathrm{PEH}$ was completed using just three lithography steps, conventional silicon substrate with full control of the cantilever thickness, in addition to the thickness of the proof mass. As the AlN deposition was conducted at a temperature of $\approx 330{ }^{\circ} \mathrm{C}$, the process can be implemented into standard complementary metal oxide semiconductor (CMOS) technology, as well as the CMOS wafer post-processing. The PEH cantilever deflection and efficiency were characterized using both laser interferometry, and a vibration shaker, respectively. This technology could become a core feature for future CMOS-based energy harvesters.
\end{abstract}

Keywords: AlN; micro-electro-mechanical systems (MEMS) cantilever; complementary metal oxide semiconductor (CMOS) compatible; energy harvesting; high performance

\section{Introduction}

Energy harvesting has recently attracted significant attention as a key power source where changing batteries in applications is not practical, or in low-power autonomous sensors and micro-devices, as a replacement of electrochemical batteries.

Several methods of harvesting ambient energies have been investigated, including solar energy, wind, flowing water, waste heat, electromagnetic waves, or vibrations [1,2]. However, most of them require the outside environment. The utilization of mechanical vibrations represent a suitable alternative for any environment, including indoors, as well as low-power autonomous sensors and microdevices [3].

Electrostatic and electromagnetic induction, and piezoelectricity can all typically be exploited as transducing mechanisms to convert mechanical energy into electrical [4]. However, from these, piezoelectric energy harvesters (PEHs) exhibit high-energy density and are, therefore, more suitable for practical applications [5]. Moreover, piezoelectric materials have an inherent capability to directly 
convert mechanical stress/strain energy into electrical energy, therefore, such devices are compact and possess simpler designs, compared to their electromagnetic and electrostatic counterparts. Furthermore, such devices can be fabricated by micromachining techniques and directly integrated into monolithic, micro-electro-mechanical systems (MEMS) [6].

Numerous piezoelectric materials were investigated for energy harvesting in MEMS applications, but the most commonly used are $\mathrm{ZnO}$ [7], lead zirconate titanate (PZT) [8,9], polyvinylidene fluoride (PVDF) [10], and AlN [11]. In particular, AlN, prepared by sputtering, can be implemented in standard complementary metal oxide semiconductor (CMOS) technology, as well as the CMOS wafer post-processing [12], thereby, enabling the integration of $\mathrm{PEH}$ with active devices. Other piezoelectric materials such as PZT, ZnO, and PVDF possess contamination risks for CMOS processing lines [13], while AlN, deposited by the metal-organic chemical vapor deposition (MOCVD) technique, requires high temperature, which prohibits its integration with CMOS devices.

Sputtered AlN is a promising material for $\mathrm{PEH}$ applications, due to low-temperature preparation, unique physical properties (such as a high thermal stability, with a melting point of $\approx 2100{ }^{\circ} \mathrm{C}$ and piezoelectric effect up to temperatures of $\approx 1150{ }^{\circ} \mathrm{C}$; high longitudinal velocity of $\approx 11,000 \mathrm{~m} \cdot \mathrm{s}^{-1}$; and wide band gap of $\approx 6.2 \mathrm{eV}$ ), high level of mechanical stiffness, and good piezoelectric and dielectric properties [11].

The single side clamped cantilever structure, due to its simple design and fabrication, is a convenient device to characterize properties of PEHs: It can produce large mechanical strain within the piezoelectric layer with its vibrations [14]. The amplitude of generated piezoelectric voltage and power depends on the device's working frequency, as well as the value of induced strain. The first resonance frequency $\left(f_{\mathrm{r}}\right)$ of a cantilever is the lowest vibrational mode, exhibiting the highest achievable strain and displacement. The goal of the harvester design is to operate at the $f_{\mathrm{r}}$ to achieve maximum power output.

Normalized power density $(N P D)$, together with output power $(P)$ and frequency range, also known as bandwidth $(B W)$, are the most widely used metrics to evaluate the performance of PEH [15]. They enable the comparison of different PEHs and provide necessary information for figure of merit (FoM) calculations [16],

$$
F o M=N P D \times B W
$$

where the NPD is defined as $P$ divided by the effective volume $(V)$ and the square of the input acceleration $(A)$,

$$
N P D=\frac{P}{V \cdot A^{2}}
$$

and where $B W$ is defined as,

$$
B W=f_{2}-f_{1}
$$

where $f_{1,2}$ are half-power, cut-off frequencies, also known as full width at half maximum (FWHM). Bandwidth comparison is often complicated, as its definition is not standardized: Sometimes it is defined by frequencies at FWHM of the spectrum, by $1 \mathrm{~dB}$ or $3 \mathrm{~dB}$ bandwidth, or the data is not available.

Fabrication of PEHs is notoriously complex, requiring five or more lithography steps, in addition to expensive silicon-on-insulator (SOI) substrates. Here we show a simple method to prepare PEH with a high value of piezoelectric coefficients of $(7.33 \pm 0.08) \mathrm{pC} \cdot \mathrm{N}^{-1}$, using low temperature ion-assisted deposition, making it fully CMOS-compatible, including the CMOS wafer post-processing.

\section{Materials and Methods}

\subsection{Chip Design and Fabrication}

Technology flow and layout were designed to allow all thin films to be deposited sequential inside the sputtering system. This is a key feature, as it enables the deposition of all layers without breaking the vacuum, thereby, resulting in high-quality layers and good adhesion between them, while eliminating contamination and achieving a high performance in the piezoelectric layer. 
The beam and proof mass had dimensions of $2000 \mu \mathrm{m} \times 4000 \mu \mathrm{m}$ and $2000 \mu \mathrm{m} \times 2000 \mu \mathrm{m}$, respectively. A piezoelectric layer between two electrodes, with dimensions of $1500 \mu \mathrm{m} \times 2000 \mu \mathrm{m}$, is placed on one end close to the fixed edge (Figure 1).
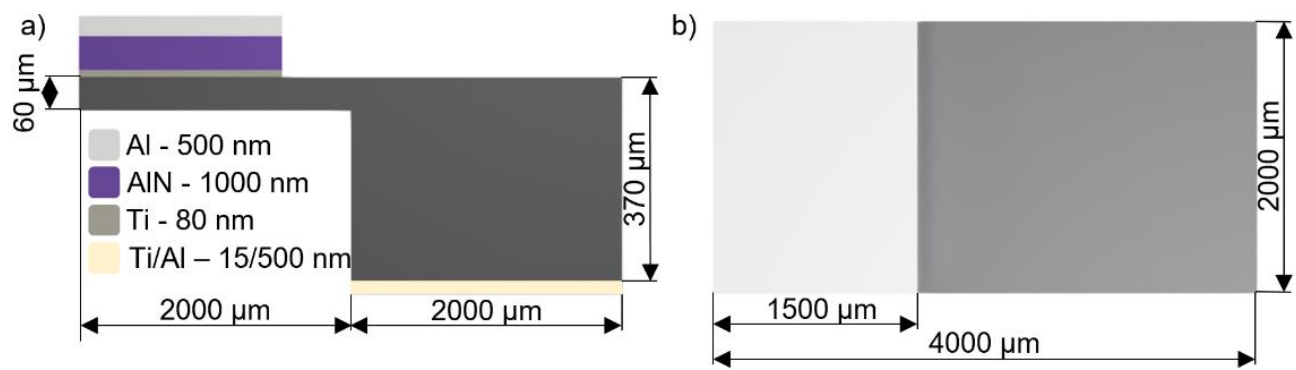

Figure 1. Layer composition and their dimensions of piezoelectric energy harvesters (PEH) (not to scale): (a) side view; (b) top view.

We had to remove a relatively large area of Si substrate, as its direct etching would result in a high loading factor and etching process instability. We designed $40 \mu \mathrm{m}$ wide trenches around the $\mathrm{PEH}$ beams, on the both sides of the substrate. Once the deep reactive ion etching (DRIE) from both sides was completed, the area surrounded by the trenches fell away from the substrate without the necessity to etch it, as demonstrated in the design in supplementary materials of previously published work [17]. A large-area substrate removal around the PEH beams led to their unobstructed movement.

The fabrication was conducted using double-side polished Si (100) N-doped wafers with a diameter of $\approx 100 \mathrm{~mm}$, thickness of $\approx 370 \mu \mathrm{m}$, and resistivity of $<0.005 \Omega \cdot \mathrm{cm}$. We deposited all sequential thin films, layer by layer (Figure 2a), using an ion-beam assisted deposition (IBAD) instrument, without breaking the vacuum between depositions. The wafers were loaded into the IBAD instrument and the system was evacuated to a base pressure of $\approx 9 \times 10^{-7} \mathrm{~Pa}$. Wafers were then pre-cleaned using a secondary ion-beam source with Ar plasma with $30 \mathrm{~V}$ beam voltage $(B V)$, for a duration of $300 \mathrm{~s}$. We then deposited $\approx 80 \mathrm{~nm}$ of $\mathrm{Ti}$, serving as a seed layer for consequent AlN (001) deposition, as well as an electrical connection between the AlN and Si substrate. We activated the primary Kaufman ion-beam source, using a $B V$ of $200 \mathrm{~V}$, resulting in a (001) oriented layer of Ti [18,19]. This was followed with a change in the $B V$ to $400 \mathrm{~V}$ and the addition of $\mathrm{N}_{2}$ to the primary ion-beam source, with a ratio of 1:1 to Ar. In addition, we employed the secondary ion-beam source for substrate bombardment, using $\mathrm{N}_{2}$ plasma at a $B V=30 \mathrm{~V}$ and performed reactive sputtering of highly (001) oriented AlN from the Al target, to achieve the desired thickness of $\approx 1000 \mathrm{~nm}[20]$.

Finally, we halted the secondary ion-beam source and $\mathrm{N}_{2}$ from the primary source and deposited the Al layer using a $B V$ of $900 \mathrm{~V}$, achieving an Al thickness of $\approx 500 \mathrm{~nm}$, suitable for subsequent wire-bonding.

The wafers were then subjected to just three lithography steps. The first lithography step was completed using positive photoresist $(\mathrm{PR})$, with a desired thickness of $\approx 1.4 \mu \mathrm{m}$, to define the shape of the top electrode, piezoelectric layer, and underneath $\mathrm{Ti}$ in a single stage. It was followed by reactive ion etching (RIE) with combined $\mathrm{Cl}_{2}$ and $\mathrm{BCl}_{3}$ gases, using an optical spectrometer to monitor the etching process (Figure $2 \mathrm{~b}$ ). After etching and PR removal, we performed the second lithography, using PR with a thickness of $\approx 10 \mu \mathrm{m}$ to define the PEH shape and the DRIE process to etch $\approx 40 \mu \mathrm{m}$ wide and $\approx 150 \mu \mathrm{m}$ deep trenches around them (Figure $2 \mathrm{c}$ ). Following this, we removed the thick PR and spin-coated, front side of the Si substrate with a standard PR to protect it; this subsequently deposited Ti and Al with a thickness of $\approx 15 \mathrm{~nm}$, and $\approx 500 \mathrm{~nm}$, respectively, on the back side of the Si wafer, forming backside electrode contact. We conducted backside lithography, with front-to-back alignment, using thick PR and etched both metals using $\mathrm{Cl}_{2} / \mathrm{BCl}_{3}$-based reaction ion etching (RIE). We continued with DRIE, through the Si substrate, until the inner parts and chips were separated from each other (Figure $2 \mathrm{~d}$ ). The thickness of PEH in areas without the proof mass was $\approx 50 \mu \mathrm{m}$. The chips were mounted individually on a supporting base of Si substrate, using a drop of Fomblin ${ }^{\circledR}$ oil, and 
etched using the DRIE method, until we reached the desired thickness (Figure 2e) of a few tens of $\mu \mathrm{m}$. The proof mass thickness was $\approx 370 \mu \mathrm{m}$, allowing us to fabricate the PEH with a high mass-to-volume ratio. The residual PR and Fomblin ${ }^{\circledR}$ were then removed with $\mathrm{O}_{2}$ plasma.

a)

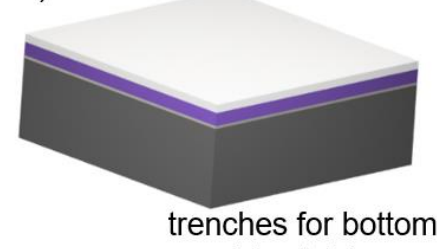

d)

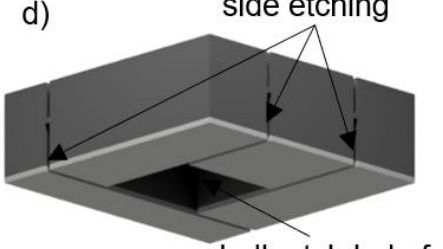

b)

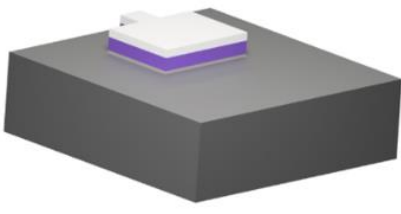

e)

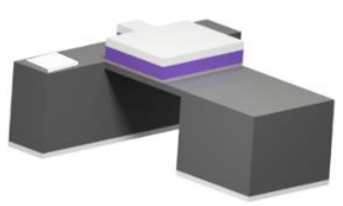

c)

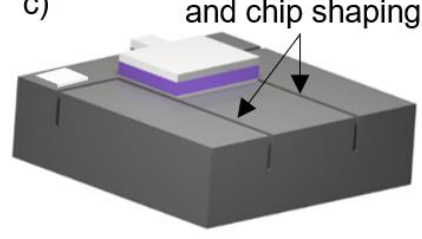

bulk etch hole for definition of the Si thickness

Figure 2. Fabrication process flow (not to scale): (a) Deposited layers on top side of Si substrate; (b) patterning of Ti/AlN/Ti/Al structure; (c) top-side trench etching using deep reactive ion etching (DRIE) method; (d) metallization followed by back-side etching causing separation of chips; (e) back-side etching, using DRIE method to form final structure.

Finally, we cut a $4.5 \times 4.5 \mathrm{~mm}^{2}$ hole, using an yttrium aluminum garnet (also known as YAG) laser into the center of the leadless chip carrier with 68 pads (LCC68). The individual chips were then mounted using silver conductive paste into the LCC68 (Figure 3a). The mounted chips had free vertical movement within the mass of the package (Figure $3 b$ ).

a)

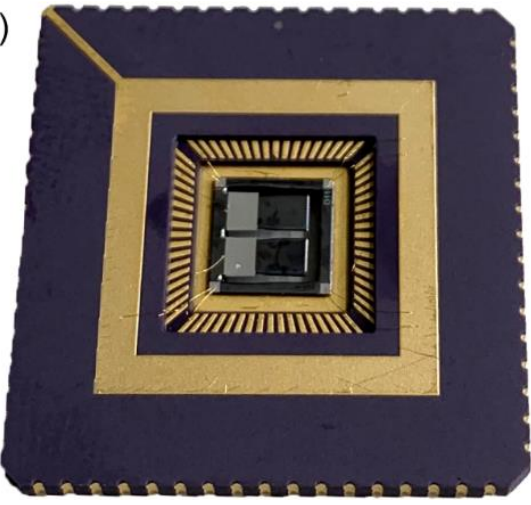

b)

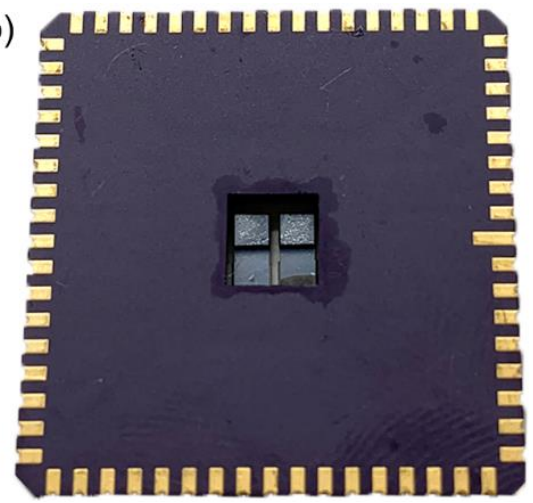

Figure 3. Fabricated PEH mounted in LCC68: (a) top view; (b) bottom view showing hole and PEH mass.

\subsection{X-Ray Characterization}

Deposited Ti and AlN layers were residual stress-free, which was determined from wafer curvature measurement. We also conducted the X-ray measurement using Bragg-Brentano setup to determine corresponding peak positions (Figure 4 ) for $2 \theta \approx 38.35^{\circ}$ for Ti (001) and $2 \theta \approx 36.06^{\circ}$ for AlN (001). These peaks positions also perfectly fit residual stress-free values determined from lattice parameters we published earlier $[18,20]$. Such prepared $(001)$ oriented AlN exhibits a high value of piezoelectric coefficient $d_{33}$ of $(7.33 \pm 0.08) \mathrm{pC} \cdot \mathrm{N}^{-1}$ along c-axis. 


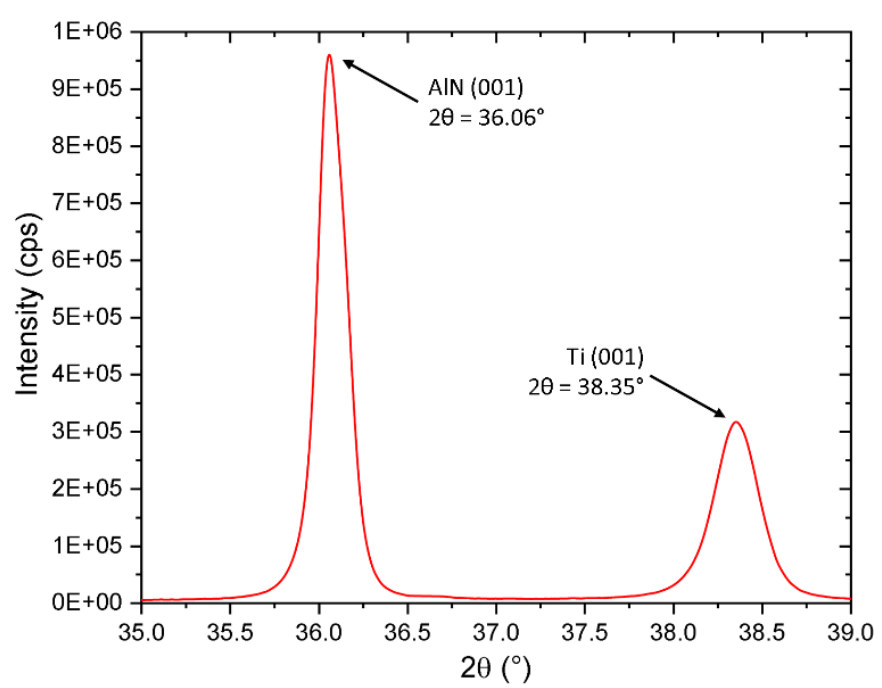

Figure 4. X-ray diffractogram determined using Brag-Brentano setup showing $2 \theta$ peak positions of $\mathrm{Ti}$ $(001) \approx 38.35^{\circ}$ and $\operatorname{AlN}(001) \approx 36.06^{\circ}$.

\subsection{Finite Element Simulation}

We performed finite element method (FEM) analyses of single clamped PEH using the ANSYS ${ }^{\circledR}$ Workbench with the Piezo and MEMS module. The model geometry was formed with a SOLID186 and SOLID226 3D element with a 20-node coupled-field, solid supporting piezoelectric analysis [21]. We performed coupled solution using an electrostatic and structural solver (Figure 5) via the piezoelectric matrix where $\{T\}$ is the stress matrix, (c) is the elastic stiffness matrix, $\{S\}$ is the elastic strain vector, (e) is the piezoelectric matrix, $\{\mathrm{E}\}$ is the electric field intensity vector, $\{\mathrm{D}\}$ is the electric flux density vector, and $\left(\varepsilon_{d}\right)$ is the dielectric permittivity matrix.

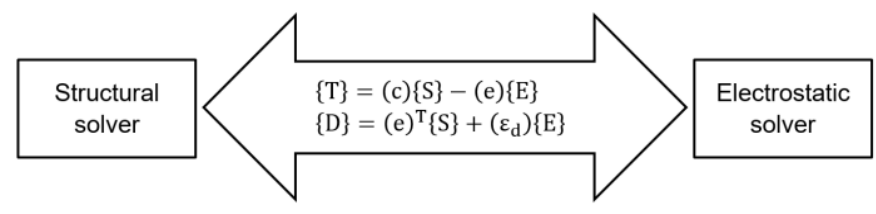

Figure 5. Scheme of coupled solution for electrostatic and structural solver, employing piezoelectric matrix.

Once we built the model, we performed modal analysis to determine resonance frequencies of the entire system. It was followed by a harmonic analysis used to determine PEH behavior under an external force, using the results from the modal analysis as boundary conditions. Then we applied the excitation voltage on electrodes to determine the displacement of $\mathrm{PEH}$ and compare it with experimental results.

Following this, we added a load resistor $\left(R_{\mathrm{L}}\right)$ into the model, applying CIRCU94 circuit 2-node beam elements using ANSYS ${ }^{\circledR}$ parametric design language (also known as APDL) commands, and examined the dependence of generated power $\left(P_{S}\right)$ on the amplitude of acceleration and the value of parallel connected $R_{\mathrm{L}}$ (Figure 6).

This task was realized as a combined analysis, involving the mechanics of a rigid body with a link to a piezoelectric effect (or the inverse piezoelectric effect) and the provision of a bond to an electrical circuit simulating $R_{\mathrm{L}}$. 


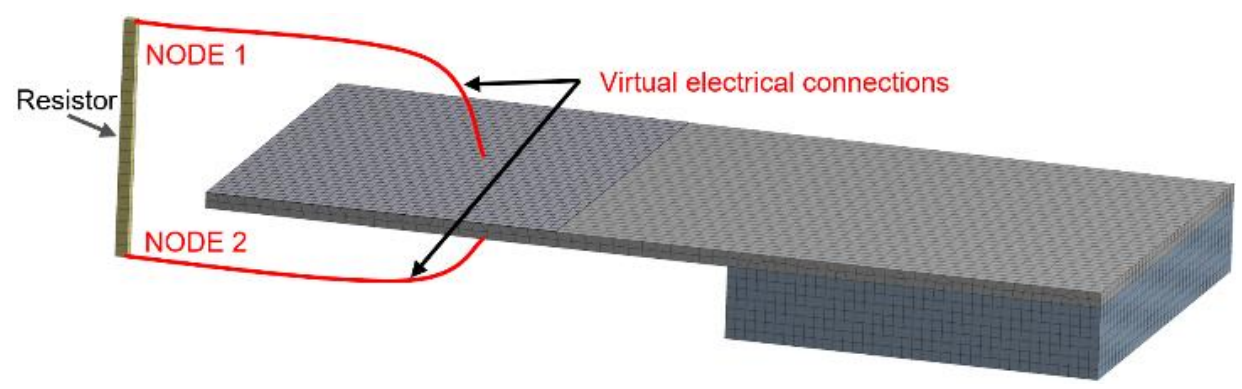

Figure 6. Scheme of PEH model with electrically connected $R_{\mathrm{L}}$.

\section{Results and Discussion}

We characterized PEHs using two methods to validate their parameters and compare them to the FEM simulations from the ANSYS ${ }^{\circledR}$ Workbench.

\subsection{Laser Interferometer Characterization}

We chose the laser interferometer measurement as the first method for resonance frequency and displacement determination (Figure 7a). We used a diode-pumped solid-state laser with single longitudinal-mode operation and output wavelength $(\lambda)$ of $\approx 532 \mathrm{~nm}$. The interferometric setup employs a classic Michelson arrangement. Illuminating light enters the polarizing beam-splitter, where it is split into two beams: The measuring beam passes to the sample, where it is reflected with phase shift into the beam splitter and on to the detector; the second (reference) beam is reflected from a fixed-reference mirror. Both beams interfere at the detector, which converts the optical signal of the incident beams into an electrical signal that is displayed on an oscilloscope (Figure 7b). The voltage power supply, with an alternate current $\left(V_{\mathrm{AC}}\right)$ and sinusoidal signal, was applied on PEH electrodes. Displacement of the PEH on z-axis $\left(D_{\mathrm{Z}}\right)$ is proportional to the number of interferometric fringes between minimum and maximum amplitudes of the exciting signal, multiplied by $\lambda / 2$.
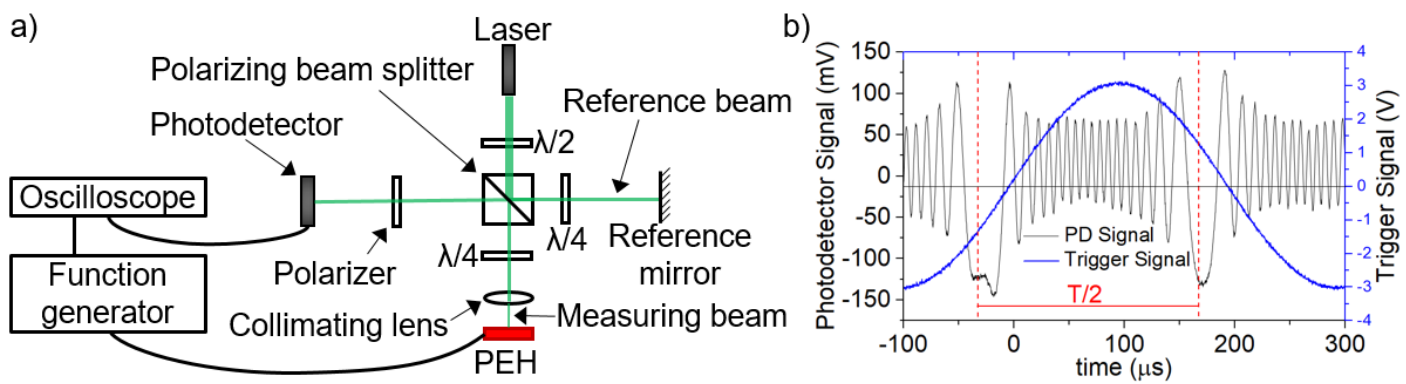

Figure 7. Interferometric measurement: (a) setup; (b) oscilloscope electrical signal.

The $V_{\mathrm{AC}}$ with a sinusoidal signal was applied on $\mathrm{PEH}$ electrodes. We adjusted $V_{\mathrm{AC}}$ within a range of $0.05 \mathrm{~V}$ to $0.2 \mathrm{~V}$. We observed the first $f_{\mathrm{r}}$ at $\approx 2520 \mathrm{~Hz}$, which agrees with results obtained by simulations with the corresponding value of $\approx 2500 \mathrm{~Hz}$. The $D_{\mathrm{Z}}$ obtained from the measurement at $f_{\mathrm{r}}$ varied within a range of $\approx 4.5 \mu \mathrm{m}$ to $\approx 18.2 \mu \mathrm{m}$ for different $V_{\mathrm{AC}}$, this corresponded with measurement data for a range of $\approx 4.1 \mu \mathrm{m}$ to $\approx 17.1 \mu \mathrm{m}$ for the same $V_{\mathrm{AC}}$ values. The dependence of measured $D_{\mathrm{Z}}$ on frequency is shown in Figure 8a. The measured values of $D_{Z}$ correlate with values determined in FEM analyses in Figure $8 b$. 


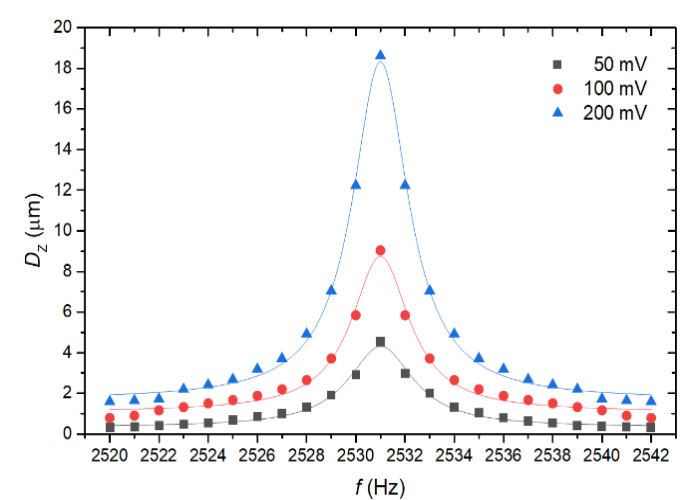

(a)

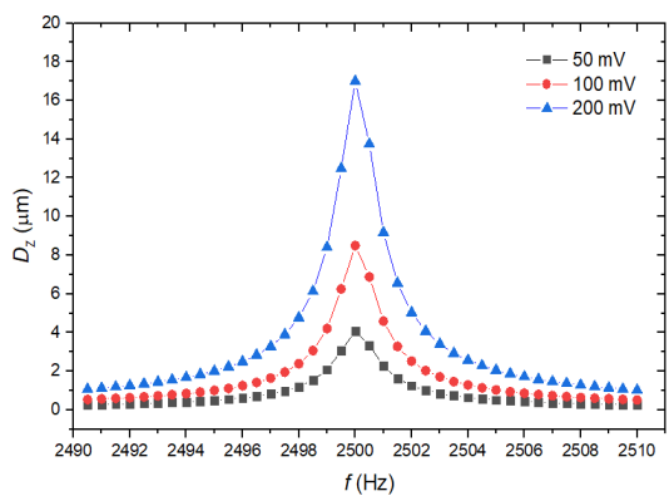

(b)

Figure 8. (a) Measured $D_{\mathrm{Z}}$ at $f_{\mathrm{r}}=2520 \mathrm{~Hz}$ with various $V_{\mathrm{AC}}$. (b) The results of FEM simulations for the same $V_{\mathrm{AC}}$ bias.

\subsection{Vibrational Characterization}

Next, we characterized generated power $\left(P_{\mathrm{M}}\right)$ using an automatized measurement system (Figure 9) [22].

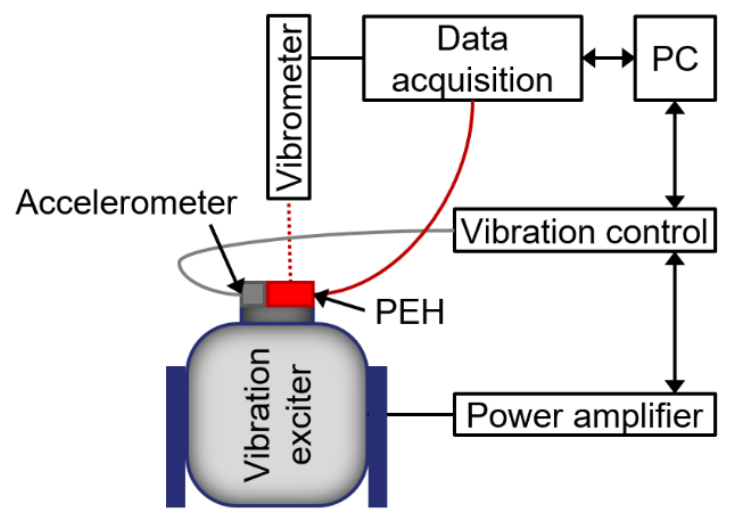

Figure 9. Measurement setup, based on vibration excitation of $\mathrm{PEH}$ for determination of $P_{\mathrm{M}}$.

We placed the PEH on a table with controlled sinusoidal vibrations of specific amplitude and frequency, near to the first $f_{\mathrm{r}}$, as extracted from the previous interferometric measurement. The test system was able to determine the $f_{\mathrm{r}}$ value, thus, we performed the measurement in proximity to this value. The measurement started by connecting an $R_{\mathrm{L}}$ to the $\mathrm{PEH}$, while the stage was vibrating. Once the amplitude of the vibrations was stabilized, we recorded voltage across $R_{\mathrm{L}}\left(V_{\mathrm{RL}}\right)$ amplitude, together with the free end of PEH displacement. The power output of the harvester was calculated from the known $R_{\mathrm{L}}$ and $V_{\mathrm{RL}}$ [23]. This procedure was then performed repeatedly for all pre-set combinations of $R_{\mathrm{L}}$, frequencies, and amplitudes.

We observed a slight shift in $f_{\mathrm{r}}$ in comparison to the $f_{\mathrm{r}}$ determined during interferometric measurement. We changed the $R_{\mathrm{L}}$ in the range from $100 \Omega$ to $1 \mathrm{M} \Omega$, with a logarithmic stepping for frequencies in a range of $2476 \mathrm{~Hz}$ to $2484 \mathrm{~Hz}$ with constant $A \approx 0.5 \mathrm{~g}$. The optimized $R_{\mathrm{L}}$ value of $\approx 67.56 \mathrm{k} \Omega$ was found for maximal generated $P_{\mathrm{M}}$ of $\approx 0.91 \mu \mathrm{W}$ at $f_{\mathrm{r}}$ with $A \approx 0.5 \mathrm{~g}$ (Figure 10a).

We also determined the dependence of $P_{\mathrm{M}}$ on $A$ for maximized $R_{\mathrm{L}}$. The obtained values showed a remarkable correlation between predicted parameters from FEM analyses and the one of the fabricated device (deviation lower than $1 \%$ ). We observed values of $P_{\mathrm{M}}$ in the range of $\approx 0.25 \mu \mathrm{W}$ to $\approx 10.33 \mu \mathrm{W}$ for the $A$ in the range of $\approx 0.25 \mathrm{~g}$ to $\approx 2 \mathrm{~g}$ at $f_{\mathrm{r}}$ (Figure $10 \mathrm{~b}$ ). 
Additionally, we identified a difference of $\approx 1.6 \%$ between the $f_{\mathrm{r}}$ determined from interferometric and vibrometer measurements.

We subsequently calculated $N P D$ and $B W$ values from the results obtained in the last experiment. The NPD was determined (according to the Equation (2) with an assumption that the effective volume was $\approx 1.72 \times 10^{-3} \mathrm{~cm}^{3}$ ) having a value in a range of $\approx 2.3 \mathrm{~mW} \cdot \mathrm{cm}^{-3} \cdot \mathrm{g}^{-2}$ to $\approx 1.5 \mathrm{~mW} \cdot \mathrm{cm}^{-3} \cdot \mathrm{g}^{-2}$ for $A$ in range of $0.25 \mathrm{~g}$ to $2 \mathrm{~g}$ (Figure $10 \mathrm{~b}$ ).
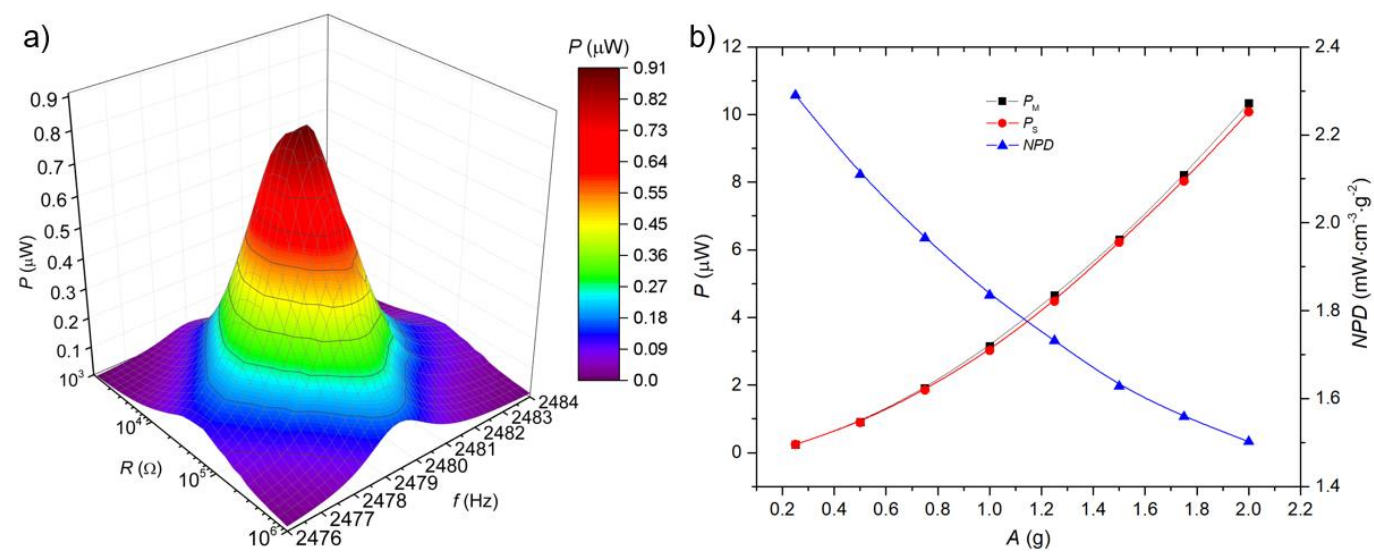

Figure 10. (a) Power spectra of measured PEH near $f_{\mathrm{r}}=2480 \mathrm{~Hz}$ with constant $A \approx 0.5 \mathrm{~g}$, (b) dependence of maximum generated $P_{\mathrm{S}}$ and $P_{\mathrm{M}}$ and calculated value of NPD on $A$.

Such values of $N P D$ are $\approx 2-10$ times higher in comparison to previously published NPD [24-28]. The $B W$ value was also determined for frequencies at FWHM of the spectrum, at a constant of $A \approx 0.5 \mathrm{~g}$ and reached a value of $\approx 2.8 \mathrm{~Hz}$.

\section{Conclusions}

This work presents a simplified method of PEH fabrication at a low temperature, using just three lithographical steps, and without the necessity of using costly SOI wafers, which dramatically reduces the manufacturing timeframes and costs. This method also allows the control of the thickness of the PEH layer from tens to hundreds of micrometers. We characterized the PEH properties using interferometric measurements, and automated power measurement using a vibration exciter. First, we applied $V_{\mathrm{AC}}$ on PEH electrodes to determine $f_{\mathrm{r}}$ and $D_{\mathrm{Z}}$, comparing them with FEM analyses to verify the model. Next, we characterized $P_{\mathrm{M}}$ at $f_{\mathrm{r}}$ and determined the optimized $R_{\mathrm{L}}$ value to maximize $P_{\mathrm{M}}$ at $\approx 67.56 \mathrm{k} \Omega$. The $\mathrm{PEH}$ generated $P_{\mathrm{M}}$ in a range of $\approx 0.25 \mu \mathrm{W}$ to $\approx 10.33 \mu \mathrm{W}$ for $A$ in a range of $\approx 0.25 \mathrm{~g}$ to $\approx 2 \mathrm{~g}$, respectively. The determined $N P D$ and $B W$ values performed better than those of previously published studies, making the proposed technology highly promising for the future development of CMOS-compatible piezoelectric harvesters.

Author Contributions: I.G., J.K. (Jaroslav Klempa), J.B. and J.P. conceived of the idea of this work, designed and fabricated chips and performed the experiments. P.V. performed finite element simulations, J.H. and M.H. performed laser interferometer characterization, J.K. (Jan Kunz) and P.N. performed the vibrational characterization. All co-authors offered helpful discussions and analyses of the results and wrote the manuscript. All authors have read and agreed to the published version of the manuscript.

Funding: The work was supported by the Grant Agency of the Czech Republic under contract GJ18-06498Y and CEITEC Nano Research Infrastructure (ID LM2015041, MEYS CR, 2016-2019), CEITEC Brno University of Technology (BUT). The infrastructure of the SIX Center of BUT was utilized to conduct the experiments. This work was also supported by the BUT specific research program (project No. FEKT-S-17-4595).

Conflicts of Interest: The authors declare no conflict of interests. 


\section{References}

1. Liu, H.C.; Zhong, J.W.; Lee, C.; Lee, S.W.; Lin, L.W. A comprehensive review on piezoelectric energy harvesting technology: Materials, mechanisms, and applications. Appl. Phys. Rev. 2018, 5, 041306. [CrossRef]

2. Du, Y.; Xu, J.; Paul, B.; Eklund, P. Flexible thermoelectric materials and devices. Appl. Mater. Today 2018, 12, 366-388. [CrossRef]

3. Toshiyoshi, H.; Ju, S.; Honma, H.; Ji, C.H.; Fujita, H. MEMS vibrational energy harvesters. Sci. Technol. Adv. Mater. 2019, 20, 124-143. [CrossRef] [PubMed]

4. Meninger, S.; Mur-Miranda, J.O.; Amirtharajah, R.; Chandrakasan, A.; Lang, J.H. Vibration-to-electric energy conversion. IEEE Trans. Very Large Scale Integr. (VLSI) Syst. 2001, 9, 64-76. [CrossRef]

5. Tian, W.C.; Ling, Z.Y.; Yu, W.B.; Shi, J. A Review of MEMS Scale Piezoelectric Energy Harvester. Appl. Sci. 2018, 8, 645. [CrossRef]

6. Todaro, M.T.; Guido, F.; Mastronardi, V.; Desmaele, D.; Epifani, G.; Algieri, L.; De Vittorio, M. Piezoelectric MEMS vibrational energy harvesters: Advances and outlook. Microelectron. Eng. 2017, 183, 23-36. [CrossRef]

7. Wang, P.H.; Du, H.J. ZnO thin film piezoelectric MEMS vibration energy harvesters with two piezoelectric elements for higher output performance. Rev. Sci. Instrum. 2015, 86, 075002. [CrossRef]

8. Tian, Y.W.; Li, G.M.; Yi, Z.R.; Liu, J.Q.; Yang, B. A low-frequency MEMS piezoelectric energy harvester with a rectangular hole based on bulk PZT film. J. Phys. Chem. Solids 2018, 117, 21-27. [CrossRef]

9. Yeo, H.G.; Ma, X.K.; Rahn, C.; Trolier-McKinstry, S. Efficient Piezoelectric Energy Harvesters Utilizing (001) Textured Bimorph PZT Films on Flexible Metal Foils. Adv. Funct. Mater. 2016, 26, 5940-5946. [CrossRef]

10. Toprak, A.; Tigli, O. MEMS Scale PVDF-TrFE-Based Piezoelectric Energy Harvesters. J. Microelectromech. Syst. 2015, 24, 1989-1997. [CrossRef]

11. Fei, C.; Liu, X.; Zhu, B.; Li, D.; Yang, X.; Yang, Y.; Zhou, Q. AlN piezoelectric thin films for energy harvesting and acoustic devices. Nano Energy 2018, 51, 146-161. [CrossRef]

12. Conrad, H.; Schmidt, J.U.; Pufe, W.; Zimmer, F.; Sandner, T.; Schenk, H.; Lakner, H. Aluminum Nitride-A promising and Full CMOS Compatible Piezoelectric Material for MOEMS Applications. Proc. SPIE 2009, 7362, 73620J.

13. Doll, J.C.; Petzold, B.C.; Ninan, B.; Mullapudi, R.; Pruitt, B.L. Aluminum nitride on titanium for CMOS compatible piezoelectric transducers. J. Micromech. Microeng. 2009, 20, 025008. [CrossRef] [PubMed]

14. Zhao, X.Q.; Shang, Z.G.; Luo, G.X.; Deng, L.C. A vibration energy harvester using AlN piezoelectric cantilever array. Microelectron. Eng. 2015, 142, 47-51. [CrossRef]

15. Yang, Z.; Zhou, S.; Zu, J.; Inman, D. High-Performance Piezoelectric Energy Harvesters and Their Applications. Joule 2018, 2, 642-697. [CrossRef]

16. Hadas, Z.; Smilek, J. Efficiency of vibration energy harvesting systems: Technology, Components and System Design. In Energy Harvesting for Wireless Sensor Networks; Kanoun, O., Ed.; De Gruyter: Berlin, Germany, 2018; pp. 45-64.

17. Ahrberg, C.D.; Ilic, B.R.; Manz, A.; Neuzil, P. Handheld real-time PCR device. Lab Chip 2016, 16, 586-592. [CrossRef]

18. Gablech, I.; Caha, O.; Svatos, V.; Pekarek, J.; Neuzil, P.; Sikola, T. Stress-free deposition of [001] preferentially oriented titanium thin film by Kaufman ion-beam source. Thin Solid Films 2017, 638, 57-62. [CrossRef]

19. Gablech, I.; Svatos, V.; Caha, O.; Hrabovsky, M.; Prasek, J.; Hubalek, J.; Sikola, T. Preparation of (001) preferentially oriented titanium thin films by ion-beam sputtering deposition on thermal silicon dioxide. J. Mater. Sci. 2016, 51, 3329-3336. [CrossRef]

20. Gablech, I.; Svatoš, V.; Caha, O.; Dubroka, A.; Pekárek, J.; Klempa, J.; Neužil, P.; Schneider, M.; Šikola, T. Preparation of high-quality stress-free (001) aluminum nitride thin film using a dual Kaufman ion-beam source setup. Thin Solid Films 2019, 670, 105-112. [CrossRef]

21. Mallik, P.K.S.; Rao, D.S. Vibration control on composite beams with multiple piezoelectric patches using finite element analysis. Int. Res. J. Eng. Technol. 2017, 4, 6.

22. Kunz, J.; Fialka, J.; Benes, P.; Havranek, Z. An Automated measurement system for measuring an overall power efficiency and a characterisation of piezo harvesters. J. Phys. Conf. Ser. 2018, 1065, 202008. [CrossRef]

23. Erturk, A.; Inman, D.J. Piezoelectric Energy Harvesting; Wiley: Hoboken, NJ, USA, 2011; ISBN 978-0470682548. 
24. Minh, L.V.; Kuwano, H. Highly Efficient Piezoelectric Micro-Energy Harvesters with Aln Thin Films Grown Directly on Flexible Ti Foils. In Proceedings of the 2017 IEEE 30th International Conference on Micro Electro Mechanical Systems (MEMS), Las Vegas, NV, USA, 22-26 January 2017; pp. 833-836.

25. Nabavi, S.; Zhang, L.H. Nonlinear Multi-Mode Wideband Piezoelectric MEMS Vibration Energy Harvester. IEEE Sens. J. 2019, 19, 4837-4848. [CrossRef]

26. Iannacci, J.; Sordo, G.; Schneider, M.; Schmid, U.; Camarda, A.; Romani, A. A Novel Toggle-Type MEMS Vibration Energy Harvester for Internet of Things Applications. In Proceedings of the 2016 IEEE SENSORS, Orlando, FL, USA, 30 October-3 November 2016.

27. He, X.M.; Wen, Q.; Lu, Z.; Shang, Z.G.; Wen, Z.Y. A micro-electromechanical systems based vibration energy harvester with aluminum nitride piezoelectric thin film deposited by pulsed direct-current magnetron sputtering. Appl. Energy 2018, 228, 881-890. [CrossRef]

28. Jia, Y.; Seshia, A.A. Power Optimization by Mass Tuning for MEMS Piezoelectric Cantilever Vibration Energy Harvesting. J. Microelectromech. Syst. 2016, 25, 108-117. [CrossRef]

(C) 2020 by the authors. Licensee MDPI, Basel, Switzerland. This article is an open access article distributed under the terms and conditions of the Creative Commons Attribution (CC BY) license (http://creativecommons.org/licenses/by/4.0/). 